Practical Applications of the Punched Card Method in Colleges and Universities

Edited by G. W. Baehne. Pp. xxiii +442. (New York : Columbia University Press ; London : Oxford University Press, 1935.) 22s. 6d. net.

THE use of tabulating machines of the Hollerith electric or other types for statistical and recording work of all kinds has increased to a remarkable extent during the past fifty years. It is not, however, generally appreciated how valuable these devices have proved themselves not only in large-scale and intricate accountancy systems but also in actual statistical research in the wide and varied field of social science. The present work describes their use mainly in colleges and universities, for example, in the registrar's and business office and miscellaneous administrative applications, and in psychological, educational, medical, hospital, legal and agricultural research. In their present wonderfully improved form, the Hollerith machines work automatically with such speed and unerring accuracy in complicated statistical manipulations that, to the uninitiated, they seem like uncanny 'robots' of superhuman efficiency.

The experience of the large number of American universities and other institutions here recorded shows that both in the ordinary business routine of a registrar's office and in social research of every kind, such mechanical devices are proving to be increasingly necessary, as essential indeed as mathematics, and are, as the editor rightly insists, the natural outgrowth of the statistical method of approach to modern learning. One writer in the authoritative series of papers here presented from many fields of university and institutional activity expresses the view that, with the statistical approach so perfected by these means, a precision and dependability of research in the social sciences will be secured second only to that of the physical sciences. So far from mechanising thought, the vast reduction in time spent on laborious routine will increase the time available for clear and original thinking and accurate observation.

\section{The Aliphatic Free Radicals}

By F. O. Rice and K. K. Rice. Pp. 204. (Baltimore, Md.: Johns Hopkins Press; London : Oxford University Press, 1935.) 21s. net.

THE capture of particles elusive and ephemeral by Paneth and Hofeditz has proved a turning point in the century-old controversy around the question "Do free radicals exist ?" In justice to recent developments, the Faraday Society's discussion in September 1933 centred chiefly round entities falling within the definition : "Free radicals are complexes of abnormal valency, which possess additive properties, but do not carry an electrical charge and are not free ions". The book under review is concerned with such radicals, of which "the most striking property is their short life".

The detection and incidental synthetic uses of free methyl, methylene and ethyl are lucidly described, and a hypothesis of thermal decomposition of organic vapours, consistent with many of the data, is based on the intermediate formation of free radicals. The authors are bold enough to prophesy in detail the courses of numerous reactions not yet investigated. Cognate reactions in the liquid phase are briefly discussed, and the hypothesis is extended, with some success, to the decomposition of large non-volatile organic molecules of the recurring-unit type. There are a few slips, such as the description of methyl and ethyl nitrites as "the methyl and ethyl esters of the alkyl nitrites" (p. 138).

Readers interested in the mechanism of reactions will, however, find this a useful, well-produced book with a comprehensive up-to-date bibliography limited by the scope of the title, but the price seems rather high to command a ready sale to individuals.

\section{The Hardness of Metals and its Measurement}

By Dr. Hugh O'Neill. Pp. xiv $+292+24$ plates. (London : Chapman and Hall, Ltd., 1934.) 25s. net.

Althoogh the hardness of a substance is not a physical constant, and cannot be expressed as a function of known physical constants, the idea of hardness is a familiar one, and empirical determinations of hardness play a great part in the study of materials. Methods depending on scratching now take only a subordinate place, and 'resistance to indentation' is the most generally accepted definition of hardness. The Brinell test, in which a hard ball is pressed into the object under a known load, forms the basis of most hardness testing, but the introduction of the diamond pyramid, as in the Vickers test, in place of a steel ball, has given greater precision to the test.

The author of this useful manual has made a special study of hardness, and is known as an investigator of the subject. Besides a clear account of the methods of determining hardness in the laboratory and in the workshop, the book deals fully with the influence of the time factor in deformation and with the relation of Brinell hardness to such mechanical properties as tensile strength and capacity for work hardening. The author emphasises the value of 'Meyer analysis' in the investigation of the latter property. Such subjects as resistance to abrasion and the eutting quality of tools and cutlery are also discussed. The manual will be found of the greatest value as a work of reference.

C. H. D.

Esquisse du progrès de la pensée mathématique: Des primitifs au ix ${ }^{e}$ Congrès international des Mathématiciens. Par J. Pelseneer. (Bibliothèque scientifique belge.) Pp. 161. (Paris : Hermann et Cie, 1935.) 15 francs.

IT is not the technical results of mathematical progress, but rather the development in the outlook of mathematicians, which is very ably sketched in this little book. From the primitive attempts of reckoning to the dizzy heights of contemporary mathematics, we thus have before us an ordered and most suggestive exposition of the mathematical atmospheres of the ages. Selected quotations from the leading mathematicians help us to understand the progressive changes in their interests and methods. This is an interesting contribution to the history of science. T. G. 